Results: Altogether, 129 patients (12 male) with symptomatic nodal HOA were included in this study and followed between April 2012 and January 2017. Out of these patients, 72 had erosive disease. The disease duration $(p<0.01)$ was significantly higher in patients with erosive compared with non-erosive disease. Pain $(p<0.05)$ and the number of clinically swollen joints $(p<0.05)$ were significantly higher in patients with erosive compared with non-erosive disease at baseline. There were significant progression of pain $(p<0.05)$ and the number of clinically swollen joints $(p<0.01)$ at the two years follow up. The progression in clinically swollen joint count was about $21 \%$ higher in patients with erosive disease.

According to the AUSCAN, patients with erosive compared with non-erosive disease had more pain $(p<0.05)$ and stiffness $(p<0.01)$ at baseline. Pain and stiffness, but not function, got worse $(p<0.01)$ in patients with erosive compared with non-erosive disease at the two years follow up.

US-detected pathologies such as gray-scale synovitis total score $(p<0.001)$, intensity of PDS $(p<0.01)$ and number of osteophytes $(p<0.01)$ were significantly higher in patients with erosive compared with non-erosive disease at baseline. There were improvements in gray-scale synovitis total score and intensity of PDS in patients with non-erosive disease while patients with erosive disease worsened at the two years follow up. On the other hand, the progression of US-determined osteophyte formation was observed in both groups.

Conclusions: The findings of this study show that pain and number of clinically swollen joints associated with US-detected synovial hypertrophy inflammatory signs and osteophyte formation is more severe in patients with erosive HOA than in patients with non-erosive disease. In addition, osteophyte formation is more likely to progress independent of synovial inflammation.

Acknowledgements: This work was supported by the project (Ministry of Health, Czech Republic) for consensual development of research organization 023728. Disclosure of Interest: None declared

DOI: 10.1136/annrheumdis-2017-eular.2795

\section{SAT0539 DIFFERENTIAL PROFILE OF ENDOGENOUS PEPTIDES DETECTED BY TARGETED PROTEOMICS IN HIP AND KNEE CARTILAGE SECRETOMES FROM OSTEOARTHRITIS PATIENTS}

P. Fernandez-Puente, L. Gonzalez-Rodriguez, V. Calamia, L. Lourido, M. Camacho, C. Ruiz-Romero, F.J. Blanco. Grupo de

Proteomica-PBR2-ProteoRed/ISCIII-Servicio de Reumatología., Instituto de Investigación Biomédica de A Coruña (INIBIC), Complexo Hospitalario Universitario de A Coruña (CHUAC), Sergas. Universidade da Coruña (UDC), A Coruña, Spain

Background: Peptidomics can be defined as the comprehensive, qualitative and quantitative study of all native peptides in a sample in a defined space at a defined time under defined biological conditions. LC-MS/MS targeted proteomics have been used to identify and quantify candidate molecular biomarkers in diverse range of samples, including cells, tissues, serum/plasma, and other types of body fluids.

Objectives: In the present work, we have developed a targeted method to detect a panel of endogenous peptides that were identified as released from human healthy $(\mathrm{N})$ and/or osteoarthritic $(\mathrm{OA})$ hip and knee cartilage. Secretomes were obtained separately from the wounded (WZ) and unwounded (UZ) zones of OA cartilage. The enrichment of endogenous peptides was achieved by ultrafiltration and solid phase extraction (SPE). After peptide extraction, the different peptide profiles of these secretomes were relative quantified by target proteomics.

Methods: Proteins secreted from human articular cartilage (secretomes) were obtained by culture of tissue explants [1]. The enrichment of endogenous peptides was standardized using ultrafiltration procedures and solid phase extraction with reversed phase $(\mathrm{C} 18)$ resins. A method for the targeted identification and relative quantitation of endogenous peptides by Multiple Reaction Monitoring (MRM)-mass spectrometry was developed employing cartilage secretome samples, and then applied on synovial fluid and serum. The peptides were separated by nano-LC coupled to a 5500 QTRAP mass spectrometer using stable isotope-labeled (SI) peptides as an internal control. Peptide identifications were searched using the ProteinPilot program. Data analysis was performed using the Skyline software.

Results: 23 endogenous peptides belonging to 9 proteins related with $\mathrm{OA}$, as Cartilage Oligemeric Matrix Protein (COMP), Cartilage Intermediate Layer Protein (CILP), Prolargin (PRELP), Dermcidin (DCD), Fibronectin (FINC) and Glia Derived Nexin (GDN) among others, were differentially detected and relatively quantified in the cartilage secretomes. Some of the endogenous peptides belonging to COMP, FINC and GDN were found with a significant high release in the UZ of hip cartilage, however in knee cartilage the release is higher in the WZ. On the other hand, certain peptides belonging to proteins like CILP or PRELP were found to be mostly increased in the UZ of both hip and knee OA cartilages when compared to healthy tissue.

Conclusions: A panel of endogenous peptides has been identified in articular cartilage, which are differentially released between OA and healthy patients, as well as between knee and hip OA patients. These endogenous peptides may be potential biomarkers to differentiate osteoarthritis from hip and knee. Our targeted proteomics approach would be widely applicable to quantify low abundant peptides of interest in complex biological samples as synovial fluid and serum in order to unravel their putative biomarker value for osteoarthritis.
References:

[1] Lucía Lourido et al. "Quantitative Proteomic Profiling of Human Articular Cartilage Degradation in Osteoarthritis". J Proteome Res. 2014 Dec 5;13(12):6096-106.

Disclosure of Interest: None declared

DOI: 10.1136/annrheumdis-2017-eular.6185

\section{SAT0540 THE REDUCTION IN ADRENERGIC AND INFLAMMATORY SERUM MARKERS IN OSTEOARTHRITIS PATIENTS AFTER TREATMENT WITH CHONDROITIN SULFATE/GLUCOSAMINE HYDROCHLORIDE AND CELECOXIB IS DIFFERENT ACCORDING TO THE PRESENCE OF BACTERIAL DNA IN BLOOD}

P. Zapater $^{1}$, M. Herrero ${ }^{2}$, H. Martínez ${ }^{2}$, R. Francés ${ }^{3,4}$, J. Vergés ${ }^{5}$, J.F. Horga ${ }^{6}$ ${ }^{1}$ Pharmacology Department, Miguel Hernández University, Alicante; ${ }^{2}$ Clinical R\&D, Bioiberica, Barcelona; ${ }^{3}$ CIBERehd. Instituto de Salud Carlos III, Madrid; ${ }^{4}$ Medicine Department, Miguel Hernández University, Alicante; ${ }^{5}$ Osteoarthritis Foundation International (OAFI), Barcelona; ${ }^{6}$ Pharmacology Department, Miguel Hernández University, Alicante, Spain

Background: Inflammation in osteoarthritis (OA) has been characterized by infiltration of immune cells and secretion of cytokines into synovial tissues. Synovial macrophages production of IL-1beta and TNF-alfa is increased in response to lipopolysaccharide (LPS) suggesting a potential role of pathogenassociated molecular patterns (PAMPs) in OA development and/or evolution. Adrenergic activity have been associated with subchondral bone loss and increased osteoclast activity. Also, adrenergic activity is a main modulator of immune response to PAMPs in different settings. However,the relationship between activation of adrenergic and immune system with OA progression and treatment response remains still unknown.

Objectives: To assess the adrenergic and immune activation in OA patients according to the presence of bacterial DNA (bDNA) fragments in blood before and after Chondroitin Sulfate/Glucosamine Hydrochloride (CS/GH) or Celecoxib (CE) treatment.

Methods: Serum samples from patients participants in a 6-month controlled, double blind and randomized clinical trial comparing the analgesic efficacy of $\mathrm{CS} / \mathrm{GH}$ and CE were analyzed to determine cytokines (IL-2, IL-4, IL-6, IL-10, IL-8, IL-1beta), catecholamines (noradrenaline, adrenaline and dopamine) and the presence of endotoxin or LPS and bDNA. Results are shown as mean \pm sd or median with ranges (Q25-Q75).

Results: Samples from 100 OA patients (age: $62 \pm 8 \mathrm{yr}$.; BMI: $31 \pm 6 \mathrm{~kg} / \mathrm{m}^{2} 86$ females; VAS: $73 \pm 15$; WOMAC: $369 \pm 43$ ) treated with CS/GH (50) or CE (50) were analyzed. There were no baseline significant differences between the two treatment groups regarding demographics,clinical and experimental variables. Thirty-four patients (17-CS/GH and 17-CE) showing bDNA in blood had significantly higher levels of noradrenaline compared with patients without bDNA (1993 [1354-3183] vs. 1324 [738-1899]; $p=0.0002$ ). After 6 months, both groups of treatment showed a similar reduction in VAS and WOMAC score (pain assessment) and serum adrenaline levels independent of presence or absence of bDNA (Table 1). Thirtythree patients showed bDNA presence at the end of the study ( 23 negative and 10 positive at baseline). Patients with bDNA at 6 months after treatment showed reduced serum noradrenaline levels compared with those observed in patients with bDNA at baseline (1993 [1354-3183] vs. 1561 [1174-2193]; $p=0.0325)$. IL-8 was significantly reduced after 6 months of treatment only in patients without bDNA.There were no significant differences between baseline and 6 months samples in the other experimental variables.

\section{Table 1}

\begin{tabular}{|c|c|c|c|c|c|c|c|c|}
\hline & \multicolumn{4}{|c|}{ Baseline } & \multicolumn{4}{|c|}{6 months } \\
\hline & \multicolumn{2}{|c|}{ No bDNA } & \multicolumn{2}{|c|}{ bONA } & \multicolumn{2}{|c|}{ No bONA } & \multicolumn{2}{|c|}{ bONA } \\
\hline & CS/GH & $\mathrm{CE}$ & $\mathrm{CS} / \mathrm{GH}$ & $\mathrm{CE}$ & $\mathrm{CS} / \mathrm{GH}$ & $\mathrm{CE}$ & $\mathrm{CS} / \mathrm{GH}$ & $\mathrm{CE}$ \\
\hline Adrenaline & 98 & 100 & 92 & 98 & $78^{*}$ & $81^{\circ}$ & $76^{*}$ & $77^{*}$ \\
\hline$(\mathrm{pg} / \mathrm{ml})$ & $\mid(88-127)$ & (77-118) & (78-114) & $(75-115)$ & (65.92) & $(622.92)$ & (58.97) & $(66-105)$ \\
\hline Norddrenaline & 1357 & 1228 & 1723\# & $2765 \#$ & 1050 & 1588 & 1563 & 1528 \\
\hline$(\mathrm{pg} / \mathrm{ml})$ & (790-1693) & $(738-1967)$ & (1385-2381] & $(12322-3250)$ & (811-1600) & $\mid(882-2133 \mid$ & $(1209 \cdot 2180)$ & (1174-2229) \\
\hline ||1-8 (pg/mL) & $\begin{array}{c}5.5 \\
(1.3 .9 .4)\end{array}$ & $\begin{array}{c}5.6 \\
(1.7 \cdot 74)\end{array}$ & $\begin{array}{c}4.8 \\
(3.9 .5 .77)\end{array}$ & $\begin{array}{c}11 \\
\text { (1.9.15) }\end{array}$ & $\begin{array}{c}3.3^{*} \\
(0.0-11)\end{array}$ & $\begin{array}{c}0.0^{*} \\
(0.0 .5 .9)\end{array}$ & $\begin{array}{c}6.1 \\
(3.7-14)\end{array}$ & $\begin{array}{c}5.6 \\
(1.5-16)\end{array}$ \\
\hline VAS score & 72 & 75 & 79 & 76 & $32^{2}$ & $20^{*}$ & $37^{*}$ & $52^{*}$ \\
\hline$(0-100)$ & $(66-82)$ & $(655-81)$ & $(67-90)$ & $(70-80)$ & $(22-45)$ & $(10-60)$ & (27.50) & $(24-60)$ \\
\hline Womac score & $\begin{array}{c}364 \\
(341.389)\end{array}$ & $\begin{array}{c}354 \\
(321-389)\end{array}$ & $\begin{array}{c}382 \\
(3724077)\end{array}$ & $\begin{array}{c}330 \\
(340 \cdot 400)\end{array}$ & $\begin{array}{c}150^{*} \\
(87-217)\end{array}$ & $\begin{array}{c}1135^{*} \\
(64-238)\end{array}$ & $\begin{array}{c}180^{*} \\
(842218)\end{array}$ & $\begin{array}{c}282^{*} \\
(139 \cdot 318)\end{array}$ \\
\hline
\end{tabular}

Conclusions: OA patients show bDNA fragments in blood associated to higher serum noradrenaline levels. Six month treatment with $\mathrm{CS} / \mathrm{GH}$ or CE reduces significantly and in a similar fashion the pain intensity and adrenaline levels. IL-8 levels were reduced with the treatment except in patients with presence of bDNA fragments in blood. Systemic adrenergic and inflammatory activity in OA patients is influenced by the presence of PAMPs as bDNA in blood and this may be a factor to take into consideration to evaluate the severity, evolution and response to treatments. 
Disclosure of Interest: None declared

DOI: 10.1136/annrheumdis-2017-eular.6147

\section{SAT0541 INHIBITING $\alpha$ V $\beta 3$ INTEGRIN AND CD47 SIGNALING AMELIORATES THE PROGRESSION OF OSTEOARTHRITIS}

Q. Wang ${ }^{1}$, K. Onuma ${ }^{2}$, R. Mao ${ }^{1}$, H. Wong ${ }^{1}$, W.H. Robinson ${ }^{1} .{ }^{1}$ Medicine;

${ }^{2}$ Stanford University, Stanford, United States

Background: Osteoarthritis is leading cause of disability, and its prevalence is rising due to the aging population and obesity epidemic ${ }^{1}$. Despite the substantial morbidity and health costs attributed to osteoarthritis, no treatment has been approved to prevent or slow disease progression, largely because the underlying pathogenic mechanism remains elusive. Both integrin $\alpha \mathrm{V} \beta 3$ and the integrin-associated receptor CD47 are considered important therapeutic targets for a number of diseases, but the potential involvement of these receptors in osteoarthritis remains unclear ${ }^{2}$.

Objectives: Our study aimed at assessing the role of integrin $\alpha \mathrm{V} \beta 3$ and the integrin-associated receptor CD47 signaling pathways in the pathogenesis of osteoarthritis, and identifying potential targets for disease-modifying therapy.

Methods: We performed transcriptomic and proteomic analyses of human and murine osteoarthritic tissues to examine the involvement of integrin $\alpha \mathrm{V} \beta 3$ and CD47 with osteoarthritis. Further, we evaluated the effects of genetic deficiency in and pharmacological modulations of integrin $\alpha \mathrm{V} \beta 3$ subunits, CD47, and their downstream signaling molecules Fyn and FAK on the destabilization of the medial meniscus (DMM) mouse model. Additionally, we used microPET/CT imaging of the DMM mouse model to assess the ligand-binding capacities of integrin $\alpha \mathrm{V} \beta 3$ and CD47 in osteoarthritic joints. Finally, we carried out multiple in vitro assays to determine how integrin $\alpha \mathrm{V} 33$ and CD47 signaling might become activated in osteoarthritis, and what the molecular consequences of such activation might be. Results: Our transcriptomic and proteomic analyses revealed the involvement of dysregulated integrin $\alpha \mathrm{V} \beta 3$ and CD47 signaling in osteoarthritis. Data from investigations of genetically deficient mice and pharmacological modulations showed that $\alpha \mathrm{V} \beta 3, \mathrm{CD} 47$, Fyn, and FAK are crucial to the pathogenesis of arthritis. We detected elevated ligand-binding capacities of integrin $\alpha \mathrm{V} \beta 3$ and CD47 in osteoarthritic joints by microPET/CT imaging of mice subjected to DMM. Our in vitro studies demonstrated that chondrocyte breakdown products, derived from the articular cartilage of individuals with osteoarthritis, induced $\alpha \mathrm{V} \beta 3 / \mathrm{CD} 47$ dependent expression of inflammatory and degradative mediators, and revealed that the signaling network involved the Ras-CRAF-MEK-ERK pathways.

Conclusions: Our findings identify a central role of deregulated $\alpha$ V $\beta 3$ and CD47 signaling in the pathogenesis of osteoarthritis, and provide a rationale for targeting these signaling pathways as a disease-modifying therapy.

\section{References:}

[1] Lawrence, R. C. et al. Estimates of the prevalence of arthritis and other rheumatic conditions in the United States. Part II. Arthritis Rheum 58, 26-35, doi:10.1002/art.23176 (2008).

[2] Tian, J., Zhang, F. J. \& Lei, G. H. Role of integrins and their ligands in osteoarthritic cartilage. Rheumatology international 35, 787-798, doi: 10. 1007/s00296-014-3137-5 (2015).

Acknowledgements: We thank Tamsin M. Lindstrom for her scientific input. Our research is supported by VA I01BX002345, I01RX000934, and I01RX000588.

Disclosure of Interest: None declared

DOI: 10.1136/annrheumdis-2017-eular.7024

\section{SAT0542 SUBCLINICAL CRYSTAL ARTHROPATHY MIGHT INFLUENCE FUNCTIONAL DISABILITY IN PATIENTS WITH KNEE OSTEOARTHRITIS? AN EGYPTIAN CROSS SECTIONAL STUDY}

R.H.A. Mohammed. Department of Rheumatology and Rehabilitation, MD FRCP, FACR, School OF MEDICINE, Cairo University Hospitals, Cairo, Egypt

Background: Osteoarthritis is a complex slowly progressive degenerative disease that affects joint components. Concomittant articular crystal deposits are able to stimulate an inflammatory response in $O A$ through stimulation of the innate immune system.

Objectives: Assess the contribution of sonographically detected crystal deposits to pain severity and functional disability in patients with knee OA (WOMAC score) Methods: Single-center cross sectional study. Adult patients diagnosed with knee OA diagnosed in accordance with ACR criteria from the Department of Rheumatology and Rehabilitation, Kasr Alainy School of Medicine, Cairo University were recruited. Clinical assessment of pain and functional status in patients with knee osteoarthritis was measured using: Western Ontario and McMaster Universities Arthritis Index score. The Logic p5 ultrasound machine (GE) with linear array probe $(8-13 \mathrm{MHz})$. Examination of the articular and periarticular structures was performed by a trained rheumatologist according to the standard EULAR guidelines for exam of the knee. Serum uric acid was investigated. Plain radiography was done for comparison.

Results: 53 patients ( 44 females $83 \%$ \& 9 males $17 \%$ ) were included, mean age 53.5 years $\pm 8.3 \mathrm{SD}$, disease duration 42.5 months $\pm 49.5 \mathrm{SD}$, body mass index mean $34.9 \pm 6.3$ SD. Crystal deposits were sono-graphically diagnosed in 73 knees $(68.9 \%)$, Monosodium urate deposits found in 33 knees $(31.1 \%)$ and Calcium
Pyrophosphate Dihydrate deposits were diagnosed in 67 knees (63.2\%). Pain, stiffness and disability scores were significantly higher in OA knees with crystal deposition as compared to those without $(p<0.05)$ that was in fact resistant to conventional analgesics, chondro-protectives and physiotherapy demanding the ongoing use of NSAIDs.

Table 1. WOMAC pain, stiffness and disability scores in the studied Patients with knee OA showing sonographic evidences of CDDs versus those without

\begin{tabular}{lcccc}
\hline WOMAC score & $\begin{array}{c}\text { OA with CDDs } \\
(\text { Mean } \pm \text { SD) }\end{array}$ & $\begin{array}{c}\text { OA without CDD } \\
(\text { Mean } \pm \text { SD) }\end{array}$ & $\begin{array}{c}\text { Mann-Whitney } \\
\text { U- test } r\end{array}$ & $\begin{array}{c}\text { P-value } \\
\text { (significance) }\end{array}$ \\
\hline WOMAC pain score & $15.6 \pm 3.6(8-20)$ & $12.0 \pm 3.8(5-20)$ & 596 & $0.00^{*}$ \\
WOMAC stiffness score & $5.5 \pm 2.0(0-8)$ & $3.8 \pm 1.8(0-8)$ & 643 & $0.00^{*}$ \\
WOMAC disability score & $53.4 \pm 11.6(25-67)$ & $41.5 \pm 12.8(14-67)$ & 606 & $0.00^{*}$ \\
\hline
\end{tabular}

WOMAC $=$ Western Ontario and McMaster Universities Arthritis Index score. *Significant difference $(p \leq 0.05)$.

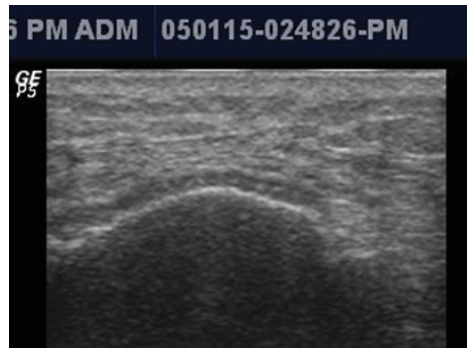

Conclusions: Crystal deposition was associated with significantly increased pain intensity, knee joint stiffness and functional disability as measured by WOMAC in patients with knee OA.

References:

[1] Altman R, Asch E, Bloch D, Bole G, Borenstein D, Brandt K, et al., Development of criteria for the classification and reporting of osteoarthritis. Classification of osteoarthritis of the knee. Diagnostic and Therapeutic Criteria Committee of the American Rheumatism Association. Arthritis Rheum. 1986; 29(8):1039-49.

[2] Naredo E, Cabero F, Palop MJ, Collado P, Cruz A, Crespo M. Ultrasonographic findings in knee osteoarthritis: A comparative study with clinical and radiographic assessment. Osteoarthr Cartil. 2005; 13(7):568-74.

Disclosure of Interest: None declared

DOI: 10.1136/annrheumdis-2017-eular.1145

\section{SAT0543 CLINICAL PREDICTORS AND RADIOGRAPHIC EVIDENCES OF OCCULT CRYSTAL DEPOSITION DISEASE WITH KNEE OSTEOARTHRITIS}

R.H.A. Mohammed. Department of Rheumatology, Rehabilitation and Clinical Immunology, MD, FRCP, FACR, School of Medicine, Cairo University Hospitals, Cairo, Egypt

Background: Osteoarthritis is a slowly progressive degenerative disorder that affects joint components from cartilage to meniscus, subchondral bones and might even lead to synovial inflammation.

Objectives: To investigate the clinical and radiographic findings associated with asymptomatic crystal deposition disease in patients with knee osteoarthritis.

Methods: A single-center cross sectional study, sixty adult patients with knee OA diagnosed according to the ACR criteria were enrolled. Participants were all subjected to history taking, general as well as musculoskeletal clinical examination, serum uric acid, and plain radiography. Examination of the knee joints for intraarticular/periarticular crystal deposits was done using a Logic p5 ultrasound machine $(\mathrm{GE})$ with linear array probe $(8-13 \mathrm{MHz})$ according to the standard EULAR guidelines.

Results: A total of sixty adult patients were enrolled, fifty three patients satisfied the inclusion criteria, 44 females $(83 \%) \& 9$ males $(17 \%)$, mean values for; ages

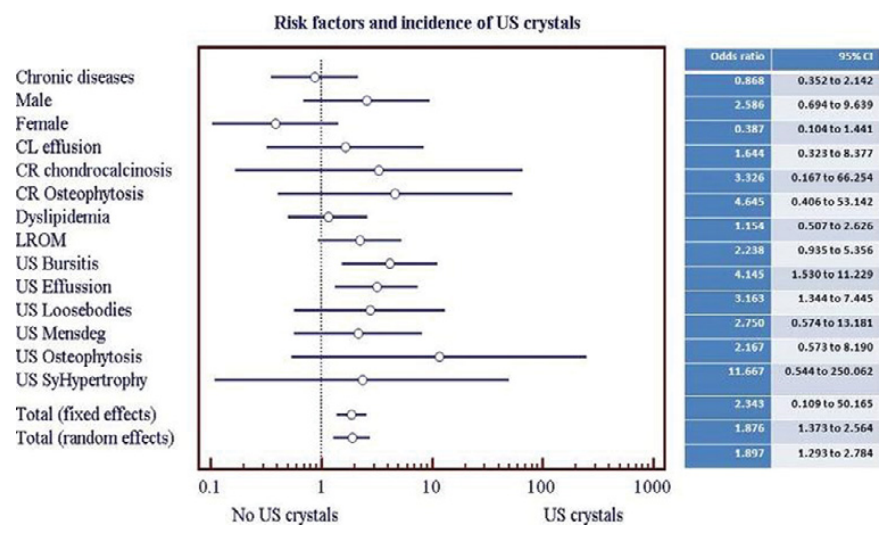

